\title{
O DIREITO INTERNACIONAL E O TRANSNACIONALISMO
}

\author{
INTERNATIONAL LAW AND TRANSNATIONALISM
}

\author{
${ }^{1}$ Jorge Mascarenhas Lasmar
}

\section{RESUMO}

$\mathrm{O}$ adensamento dos fluxos transnacionais no cenário internacional traz à tona a grande dificuldade das concepções tradicionais do Direito Internacional em se adequarem à nova realidade social. Estes fluxos vão afirmar a necessidade de se alterar o modelo clássico do Direito Internacional que se centra no Estado por um modelo que consiga se conciliar com o caráter multidimensional e as autoridades difusas das relações internacionais. $\mathrm{O}$ direito internacional deve assim expandir seu corpo normativo para incorporar a complexa teia de interdependência e correlação de poder entre os Estados-Nações e outros atores não governamentais que compõem o sistema internacional.

PALAVRAS CHAVE: Direito Internacional; Transnacionalismo; Regimes; Globalização; Ordenamentos Quasi-Jurídicos

\begin{abstract}
The increased density of the transnational flows in the international scene shed light into the great difficulty of traditional international law conceptions to deal with the new social reality. These flows show the need to change the classical international law framework that focuses on the state for one that is able to incorporate the multidimensional character and the diffuse authorities of international relations. International law should, thus, expand its normative body to incorporate the complex web of interdependency and co-relations of power amongst the nation-state and other non-governmental actors that compose the international system.
\end{abstract}

KEYWORDS: International Law; Transnationalism; Regimes; Globalization, Quasi-Legal Systems

\footnotetext{
${ }^{1}$ Doutor pela London School of Economics and Political Science, LSE, (Londres). Coordenador Geral de PósGraduação das Faculdades Milton Campos e Professor Permanente do Programa de Pós-Graduação em Relações Internacionais da Pontifícia Universidade Católica - PUC, Minas, MG, (Brasil). E-mail.: jorgelasmar@gmail.com.
} 


\section{INTRODUÇÃO}

O sistema internacional passa por um momento de profundas mudanças que se refletem, principalmente, na (re) estruturação de sua base de poder e nas relações e interações entre seus atores. $\mathrm{O}$ desenvolvimento dos meios de comunicação e o fim dos antigos sistemas políticos, associados ao aumento e diversificação dos fluxos econômicos, sociais e culturais, implicaram em uma nova configuração do cenário mundial. Na verdade, tal cenário ainda é incerto $^{2}$ e vem a ser marcado pelas discussões acerca do surgimento ou não de uma nova ordem internacional. ${ }^{3}$

Trata-se do chamado fenômeno da globalização, ${ }^{4}$ que vem acompanhado de um inevitável debate em torno do redimensionamento do Estado e do acirramento da interdependência complexa entre os atores. O surgimento de atores e fluxos não-estatais, bem como a convivência entre uma antiga e nova ordem é refletida pelas interações simultâneas entre atores interestatais, intergovernamentais e transnacionais. Estas interações resultaram na criação de um verdadeiro "espaço público transnacional". Se por um lado este "novo espaço" serve de arena para a convivência entre os mais diversos atores, por outro, cria-se uma área de interação ${ }^{5}$ em que diversos atores passam a operar livres do controle estatal, com distintas demandas, racionalidades e interesses, levantando novos desafios e limites à aplicação territorializada do direito estatal. ${ }^{6}$ Este quadro é especialmente agravado por um cenário de anarquia (BULL, 2002) em que os Estados são, ao mesmo tempo, os próprios legisladores e

\footnotetext{
${ }^{2}$ Este panorama de indefinição também se reflete no plano teórico, em que convivem modelos conflitantes, os quais dificilmente poderiam explicar os novos fenômenos que se apresentam. A pluralidade (lato sensu) é o princípio norteador das análises que visam compreender e explicar a natureza dessas mudanças, uma vez que evidencia e possibilita a convivência de diversas abordagens, bem como a permanência e interação entre novas e velhas estruturas e tradições.

${ }^{3}$ De fato, como coloca Burton, há a coexistência de dois cenários: Um, marcado pelo surgimento de novos atores, pela abertura e diversificação dos canais e fluxos de interações e pela diversificação e desierarquização da agenda internacional; outro, especialmente revitalizado após os atentados de 11 de setembro, caracteriza-se essencialmente pela posição hierarquicamente superior do Estado e das questões de segurança em um sistema "anárquico", marcado pelos jogos de interesse e poder (BURTON, 1993).

${ }^{4}$ Note-se que existe uma distinção entre os termos globalização e mundialização. Se por um lado este se refere ao encolhimento do espaço-tempo nas interações entre os diferentes povos, por outro aquele se refere às recentes mudanças do sistema internacional como o surgimento de novos atores, novos canais de comunicação, aumento da interdependência e diversificação da agenda internacional. Esta diferenciação é importante na medida em que a concepção francesa e historiográfica (mundialização) data o início deste movimento à era das Grandes Navegações, enquanto que os partidários da globalização enfocam suas análises nas recentes transformações do sistema internacional ocorridas a partir da década de 1960. É sobre esta última perspectiva que nossa análise recairá.

${ }^{5}$ Note-se que apesar da denominação "espaço público transnacional" este conceito carrega a ideia de nãoespaços de interação como a internet, por exemplo.

${ }^{6}$ Este problema é sentido tanto no âmbito do direito interno, em que o Estado perde capacidade legislativa e de aplicação normativa sobre atores e espaços não-estatais, quanto no plano do direito internacional em que a matriz voluntarista passa a ser cada vez mais questionada.
} 
destinatários das normas internacionais (PELLET et al, 2003) em um ambiente em que a geometria irregular de poder entre os atores está sempre presente (MORGENTHAU, 2003).

Desta forma, estas recentes transformações do cenário internacional trazem à tona a grande dificuldade das concepções tradicionais do Direito em se adequarem à realidade e aos novos desafios da globalização, fenômeno especialmente sentido pelo Direito Internacional.

$\mathrm{Na}$ tentativa de se buscar um alcance mais amplo das análises jurídicas dos processos e interações que têm lugar no interior do sistema internacional globalizado, surge a necessidade de se adotar novas concepções e abordagens do próprio Direito Internacional. ${ }^{7}$ Dentro desta lógica, propõe-se uma abordagem mais ampla ao programa de pesquisa ${ }^{8}$ do direito internacional. ${ }^{9}$ Esta proposta tem como objetivo dar um passo inicial na direção da correção das anomalias ${ }^{10}$ levantadas pelo processo da globalização e da busca pela heurística positiva $^{11}$ e produção de conteúdos empíricos excedentes ${ }^{12}$ do programa de pesquisa do direito internacional ao também se incluir as relações transnacionais em seu escopo.

\section{1) ENTENDENDO O FENÔMENO TRANSNACIONAL}

Os fluxos e interações transnacionais vão afirmar a necessidade de se alterar o modelo clássico do Estado, em que este é o centro das relações internacionais, por um modelo que consiga se conciliar com o caráter multidimensional e as autoridades difusas das relações internacionais. Esta mudança de enfoque analítico surge pela dificuldade de se

\footnotetext{
${ }^{7}$ Ver, por exemplo, o "direito transnacional" de Jessup, o retorno da concepção mais ampla do "direito das gentes" de Rivier e Scelle ou mesmo a de "direito das relações internacionais" de Payot.

${ }^{8}$ Segundo Lakatos, o progresso da ciência se daria a partir de programas de pesquisa que seriam "regras metodológicas que nos indicam quais caminhos deveríamos evitar na pesquisa (heurística negativa) e quais objetivos deveríamos buscar (heurística positiva). Um programa de pesquisa consiste em uma série de teorias sucessivas que competem na busca da verdade científica e que têm em comum um núcleo duro de axiomas não abertos à refutação. Ao redor deste "núcleo duro" seriam construídas diversas hipóteses adicionais formando um "anel protetor", estas sim abertas à refutação e reformulação (LAKATOS 1978).

${ }^{9}$ Para Celso Mello, "A vantagem de se estudar o aspecto político no DIP é chamar a atenção para o seu funcionamento e para a elaboração de suas normas. Até recentemente, os internacionalistas escreviam os seus livros mostrando os institutos e normas ... como se eles fossem reais e as suas violações eram vistas simplesmente como violações ao Direito e, portanto, passíveis de sanções ... O Direito Positivo nada mais é do que a ideia do direito considerado sob o ângulo político." (MELLO, 1976, p.8).

${ }^{10}$ As anomalias consistem em refutações ou falhas explicativas das bases empíricas das hipóteses auxiliares que formam o "anel protetor" do programa científico (LAKATOS, 1978).

${ }^{11}$ A heurística positiva, diretamente ligada a ideia de progresso da ciência, consiste de "um conjunto de sugestões ou pistas, parcialmente articuladas, em como mudar, desenvolver as 'variantes refutáveis' do programa de pesquisa, [ou seja,] como modificar, sofisticar o 'anel protetor' refutável." (LAKATOS, 1978, p. 50, Tradução própria).

${ }^{12}$ A reformulação da teoria frente a uma anomalia feita por um processo de heurística positiva permite que o programa de pesquisa científico tenha um avanço criando um conteúdo empírico excedente, ou seja, não apenas a explicação de fatos mas a incorporação de fatos novos que antes não eram explicados e tidos como anomalias (LAKATOS, 1978).
} 
explicar fatos que ocorrem no cenário mundial desvinculados da lógica territorial e do controle estatal tais como, por exemplo, os fluxos monetários do mercado financeiro. Assim, sob a perspectiva transnacionalista, o sistema internacional que vem se configurando é conformado por relações que ultrapassam as fronteiras políticas e territoriais e circulam, por todo o mundo, independente da localização geográfica do país e com certa liberdade dos controles estatais. Esta noção desafia não somente a ideia tradicional de Estado-Nação circunscrito a um território definido e limitado geograficamente, mas também do próprio direito (BURTON 1993).

Neste sentido, Keohane e Nye definem as relações transnacionais como contatos, coalizões e interações que operam para além das fronteiras estatais sem o controle dos órgãos centrais encarregados da execução da política exterior dos governos (KEOHANE; NYE, 1971). Primeiramente, vale ressaltar a distinção que os autores fazem entre relações internacionais e transnacionais: a primeira é derivada da política externa dos Estados, envolvendo os acordos entre duas ou mais nações e as suas ações e reações, ou seja as interações que se dão no interior do sistema internacional conforme a ordem clássica, sendo as interações transnacionais, portanto, aquelas que simplesmente ignoram as referências territoriais e localização nacional, sendo realizadas por atores que têm como dimensão de ação todo o sistema, não se limitando, pois, territorialmente (KEOHANE; NYE, 1971). Logo, dentro desta perspectiva, podemos dizer que as relações internacionais no cenário globalizado não se restringem mais ao âmbito interestatal, isto é, àquelas que se produzem entre as unidades estatais em fluxos verticais, mas se ampliaram para o âmbito transnacional, ou seja, para aquelas interações que se produzem para além das fronteiras estatais e sem passar pela chancelaria oficial contestando, assim, a ordem clássica.

Desde princípios de Vestefalia, até aproximadamente a década de 70 (século XX), os Estados consagraram-se como os principais atores do cenário internacional marcados pela independência entre as políticas externas e internas (e a conseqüente separação entre os sistemas normativos internos e internacionais), bem como pela delimitação precisa das fronteiras territoriais entre as quais se davam as interações do sistema. Este modelo pode ser entendido a partir da alegoria das "bolas de bilhar", ${ }^{13}$ que reafirma a autonomia entre as políticas internas e externas e mais, demonstra a incomunicabilidade entre o interior dos Estados e o cenário internacional (e, portanto, a sua não interação direta com o sistema

\footnotetext{
${ }^{13}$ Para Burton, as relações internacionais se dariam a partir da interação entre os Estados como bolas de bilhar se chocando umas com as outras em uma mesa de sinuca. Note-se que o interior das esferas não se comunicam (BURTON, 1993).
} 
internacional). Assim, as interações do sistema internacional eram realizadas apenas pelos governos dos Estados através da chancelaria oficial. Os atores somente eram capazes de agir internacionalmente através do Estado e em nome deste (ROSENAU, 1990). Obviamente que o direito internacional, que regulava (ao lado das relações de poder) estes fluxos, e reconhecia apenas os Estados e as organizações internacionais como sujeitos de direito, terminava por legitimar esta ordem vestefaliana. É com base neste raciocínio que podemos diferenciar três modalidades de interações no interior do sistema: As relações interestatais seriam aquelas do intercâmbio entre os governos dos Estados; as transgovernamentais seriam aquelas efetuadas por organismos do Estado, mas sem as prerrogativas tradicionais deste na projeção de seus interesses no cenário externo; e as transnacionais seriam aquelas realizadas por atores não-estatais como corporações econômicas, bancos, investidores no mercado financeiro, organizações não-governamentais (ONGs) etc (KEOHANE, NYE, 1971).

A partir destas relações, que são conectadas entre si, o sistema internacional se transformou em uma grande rede de interações cruzadas, isto é, tornou-se altamente complexo e descentralizado. Criou-se assim, uma interdependência complexa ${ }^{14}$ entre os atores já que as ações precisam ser tomadas de maneira tal que envolva uma gama maior de posições relativas. Isso faz com que o sistema se mostre cada vez mais complexo, não somente no que se refere ao processo decisório dos atores, mas também em relação aos temas da agenda internacional. Percebemos na cena internacional a atuação de agentes plurais como $\mathrm{ONGs}^{15}$, unidades subnacionais (como as cidades, partidos políticos, $\operatorname{sindicatos}^{16}$, e a própria sociedade civil), empresas multinacionais e transnacionais, movimentos ecológicos, movimentos de direitos humanos e de tráfico de drogas que passaram a compartilhar com o Estado o papel de protagonista das relações internacionais. ${ }^{17}$

A partir disso, percebemos que a ideia de transnacionalismo tem suas bases, em última instância, na noção de interdependência. Diante dos avanços científicos e tecnológicos, do crescente fluxo de trocas e circulação de mercadorias e símbolos, da

${ }^{14}$ É a partir do acirramento dos fluxos de trocas entre atores estatais e não-estatais combinado com a interdependência complexa e as novas formas de articulação e governança entre eles, é que surge o fenômeno denominado "globalização".

${ }^{15}$ Note-se que algumas Organizações Não Governamentais autorizadas têm participação, embora limitada, garantida no Conselho Econômico e Social das Nações Unidas desde sua fundação. Note-se, porém, que estas não possuem direito de voto (art. 71 da Carta das Nações Unidas) e somente a partir da década de 70 é que estes atores começaram a adquirir um certo grau de relevância e poder de atuação no cenário internacional.

${ }^{16}$ Note-se que também excepcionalmente, os sindicatos têm participação na OIT, criada desde 1919.

${ }^{17}$ Alguns atores chegam mesmo a exercer um papel de contra-hegemonia (entendida no sentido gramsciniano) de articulação contra os valores estatais, como o caso do terrorismo, do crime organizado e do tráfico de drogas e entorpecentes (BRANT, 2003). 
simultaneidade dos fluxos financeiros, da expansão do número de atores e diversificação dos temas abordados, cria-se uma verdadeira rede de relações transnacionais. Nesta rede, a interação entre os indivíduos, associações, e outros atores transnacionais, bem como a circulação de seus valores, contribuiu para a formação da ideia de uma comunidade mundial (consubstanciada, no direito internacional, pelo retorno da noção de comunidade e o surgimento de "valores" universais na disciplina, como por exemplo o jus cogens) (PELLET, 2004). Este movimento (transnacional) também gera desgaste da sociedade interestatal e na distinção entre o interno e o externo, além de promover o pluricentrismo e a multipolaridade do sistema. Esta multiplicidade de canais torna as estratégias articuladas a partir de temas específicos de acordo com determinadas conveniências, inexistindo, desta forma, uma hierarquia clara de temas, uma vez que a variedade temática faz com que a importância das questões seja decidida no decorrer das negociações. Desta forma, desde o fim da guerra fria até os atentados de 11 de setembro de 2001, quando houve uma reafirmação dos valores da ordem clássica, ocorreu inegável diminuição do papel das questões de segurança frente à interdependência, frente a esperança de que a cooperação poderia reduzir o papel dos mecanismos de coação bélica na resolução de litígios. ${ }^{18}$

Sob este raciocínio, pode-se dizer que o contexto atual é marcado por uma complexa teia de interdependência e correlação de poder entre os Estados-Nações e outros atores não governamentais que fazem parte do sistema internacional (O'BRIEN, et al, 2000). Neste cenário, cabe distinguir, em uma outra classificação, dois tipos de interações que ocorrem no sistema internacional contemporâneo: as que são de caráter global e as que são de ordem transnacional. As "interações globais" são definidas como circulação de informação, dinheiro, objetos físicos, populações e outros bens tangíveis ou intangíveis através das fronteiras estatais; já o termo "interações transnacionais" é empregado para descrever a circulação de bens tangíveis e intangíveis através das fronteiras estatais quando ao menos um ator não é um representante estatal ou de uma organização intergovernamental (KEOHANE, NYE, 1971). É neste último tipo de interação que vamos concentrar nossa análise.

\footnotetext{
${ }^{18}$ Mitrany, um dos primeiros autores que veio a estudar o fenômeno da integração nas Comunidades Europeias, argumenta que com o fenômeno do spill over, processos bem-sucedidos em uma área técnica levam à cooperação em outras áreas, passando a gerar uma necessidade de colaboração funcional em outros setores, o que pode vir a reorientar a política. Este processo ainda substitui as lealdades dos indivíduos pelo Estado por lealdades pelas novas unidades que vão se formando. Desta forma, como para Mitrany e para os demais funcionalistas, a guerra não é algo inerente ao homem, mas sim determinada pela estrutura presente no sistema internacional, o movimento da integração regional e as novas lealdades reduziriam as possibilidades de guerra (ARENAL, 1994). Esta posição merece certa consideração porque, se é verdade que hoje guerras totais entre países parecem um pouco distantes, há uma enorme eclosão de conflitos regionais suscitados exatamente de novas lealdades, e pela reivindicação de autonomia.
} 


\section{2) A Criação De Sistemas Simbólicos Meta-Jurídicos}

No contexto desta diversidade de interações se observa a prática de associação dos atores internacionais em torno de diversas áreas temáticas de interesse comum. Estas articulações resultam na criação muitas vezes espontânea de verdadeiros sistemas simbólicos meta-jurídicos que regulamentam as interações e comportamento entre eles. Em alguns casos, a complexidade normativa e a fidelidade dos atores envolvidos para com estas normas nos remetem à ideia de que tais quadros cognitivos constituem verdadeiros ordenamentos normativos privados (isto é, não-estatais). Esta conclusão se dá na medida em que são os próprios atores envolvidos quem irão determinar as regras de atuação e cooperação sem passar pelo processo legislativo tradicional dos Estados podendo, inclusive, chegar a atingir um alcance global.

Gunther Teubner (1997) aponta, neste sentido, que não apenas a economia, mas a ciência, a cultura, a tecnologia, os sistemas de saúde, os serviços sociais, o setor militar, o transporte, as comunicações e a mídia, e o turismo estão auto-reproduzindo subsistemas mundiais que concorrem com a política e o direito dos Estados-Nações (que tratam de relações inter-sistêmicas entre as unidades nacionais) e formam uma verdadeira miríade de diversas "pequenas sociedades globais" fragmentadas e dispersas. Argumenta ainda neste sentido que:

"Os regimes legais internacionais das empresas multinacionais são fortes candidatos ao direito global sem Estado. Uma combinação semelhante de globalização e informalidade pode ser encontrada no direito do trabalho. Nele, empresas e sindicatos são as fontes dominantes da produção jurídica enquanto atores privados. Os acordos técnicos e profissionais auto-regulados, tendem à coordenação em escala global com um mínimo de intervenção da política oficial internacional. $\mathrm{O}$ discurso dos direitos humanos se tornou globalizado e está pressionando pelo seu próprio ramo do direito, não apenas em busca de uma fonte outra que o Estado mas contra os próprios Estados. [...] similarmente, no campo da ecologia, existem tendências na direção da globalização legal em uma relativa insinuação às instituições estatais. E mesmo nos esportes mundiais, as pessoas estão discutindo o surgimento de uma lex sportiva internationalis." (TEUBNER, 1997, p. 4, tradução própria). 
Assim, estes blocos meta-jurídicos constituem-se como um ordenamento quasijurídico individualizado e de atuação transnacional, que foge à tradicional dicotomia entre os direito interno e o direito internacional (distinção esta claramente assentada sobre as bases territoriais vestefalianas). Não se trata, ressalta Teubner:

"[...] de um corpo legal subdesenvolvido que tem certas deficiências
estruturais em relação ao direito nacional, mas de um ordenamento
maduro distinto do direito dos Estados Nações. Estas características
podem ser explicadas pela diferenciação na sociedade internacional.
Enquanto aos "direitos globais" [regimes] falta o apoio político e
institucional em nível global, eles estão intimamente ligados aos
processos socioeconômicos globalizados."(TEUBNER, 1997, p. 4,
tradução própria).

Desta forma, este novo aspecto normativo das relações internacionais abre espaço para novas relações de autoridade que fazem frente às tradicionais relações interestatais de poder e acaba por pressionar a concepção tradicional da hierarquia kelseniana do direito. Isto porque na concepção de Kelsen, a pirâmide hierárquica que fundamenta o direito coloca o processo legislativo constitucional (legítimo) em seu topo. Todavia, com o processo de transnacionalização, o processo legislativo passa a sofrer uma enorme pressão uma vez que os regimes e as articulações dos atores não estatais passam a reivindicar um ordenamento normativo meta-hierárquico. Isto se dá na medida em que alguns atores que não têm personalidade jurídica de direito internacional (ou possuem personalidade reduzida) vão questionar o monopólio legislativo constitucional no plano doméstico dos Estados no que diz respeito à criação de normas no plano transnacional e vão reivindicar a alocação da produção normativa para este regimes meta-jurídicos. Esta reinvindicação pressiona para o reconhecimento de outras fontes normativas situadas na periferia dos sistemas legais e em processos sociais externos à produção legislativa oficial (TEUBNER, 1997, p. 4, tradução própria).

Estas proposições deixam clara a necessidade de se repensar a doutrina tradicional das fontes do direito, diante das dificuldades que o cientista jurídico vem encontrando ao apreciar a realidade segundo os conceitos tradicionais do direito. Dentro da ideia sistêmica, uma corrente que vem tentar responder a este impasse é a teoria de Luhman. Luhman, seguindo a linha do "direito vivo" da Bukowina de Ehrlich, trabalha com o direito positivo como um "conjunto de expectativas generalizadas contra-fáticas" (LUHMANN, 1995). Esta definição de direito positivo ultrapassa as decisões dos juízes e o ordenamento jurídico 
formal/positivo. Em realidade, o direito se refere às expectativas contra-fáticas que normatizam os comportamentos dos atores naquilo que se espera que aquela conduta responda positivamente ao binômio direito/não-direito. A sanção não é um elemento essencial do direito, mas apenas uma maneira de reforçar as expectativas, assim como o procedimento legislativo é apenas uma chancela destas expectativas. Ora, neste sentido, a própria noção do direito se torna eminentemente contingente uma vez que as expectativas são mutáveis e a distinção entre fonte e fundamento passa a não mais existir (LUHMANN, 1995). Nesta teoria, o direito também não obedece mais à distinção entre o direito interno e o internacional.

Deste modo, a criação destes regimes meta-jurídicos caminha para a constituição de um quasi-direito ao efetivar as expectativas contra-fáticas de atores que antes estavam excluídos do processo legislativo tradicional. Os atores transnacionais, juntamente com os Estados e as organizações internacionais, passam a constituir o próprio fundamento e fonte do direito. Logo, dentro do pensamento de Luhman, diante destas mudanças ontológicas do mundo jurídico, todo o direito clássico, nacional ou internacional, deve passar por uma reformulação epistemológica profunda a fim de se estruturar de acordo com um direito eminentemente contingente e complexo no qual não existe distinção entre o direito nacional e o internacional sobre o qual se assenta. ${ }^{19}$

\section{3) QUAL DEVE SER O PAPEL DO DIREITO INTERNACIONAL FRENTE AOS FLUXOS E ATORES TRANSNACIONAIS?}

Outro efeito deste processo é a aceitação do pluralismo das formas jurídicas dentro do sistema internacional. Uma vez que aceitamos que o sistema jurídico internacional também é composto por esta miríade de formas jurídicas, observamos que o pluralismo jurídico pode se manifestar inclusivamente ou exclusivamente. Inicialmente, o pluralismo jurídico foca sua atenção nos diversos e distintos corpos legais que surgem a partir do processo de globalização e distintos do quadro normativo estatal (TEUBNER, 1997). Nesta acepção, teríamos um pluralismo inclusivo que também pressiona o direito internacional a se reformular epistemologicamente e reconsiderar a vontade dos Estados como seu fundamento ao também levar em conta também a vontade/prática dos atores transnacionais além de incluir suas interações e fluxos no interior do sistema como objeto de sua normatização.

\footnotetext{
${ }^{19}$ Neste sentido, haveria apenas uma distinção de função dentro do direito.
} 
Neste sentido, o direito internacional passaria a também a normatizar estes regimes metajurídicos internacionais e transnacionais e reconheceria a personalidade jurídica de alguns atores transnacionais. ${ }^{20} \mathrm{O}$ direito internacional também reconheceria, desta forma, a produção normativa contemporânea como sendo complexa e contingente, desprovida de uma hierarquia entre o direito estatal e o internacional (transnacional) ao reconhecer que estes regimes são estruturas quasi-legislativas auto-reprodutoras, ou mesmo que estas relações se baseiam nos contrats sans loi. $^{21}$

Para outros, no entanto, o direito internacional deveria apenas se adaptar, sem mudanças epistemológicas profundas da forma pela qual ele se manifesta hoje, para incorporar estas relações. É talvez firmando esta posição pluralista, mas conservadora, que Alain Pellet afirma que:

"Uma tal sacralização da liberdade contratual ${ }^{22}$ é inaceitável, pelo menos por causa dos seus impasses práticos: não podendo as partes prever todas as dificuldades, nenhuma norma jurídica permitia resolver um conflito: mais a mais, na ausência de princípios de ordem pública, é a lei do mais forte que prevalecerá.

[...]

De acordo com uma terceira aproximação, os contratos transnacionais são - ou deveriam ser - submetidos ao "direito internacional público". Em apoio da sua posição, os autores invocam primeiro que tudo as vantagens práticas: especialmente o fato do direito internacional ser exterior às partes - o que não é inteiramente exato para os Estados torná-lo-ia "neutro" perante elas. Eles chamam a atenção, por outro lado, que certas sentenças arbitrais deste tipo fazem referência, quanto ao direito aplicável, a normas recebidas do direito internacional geral." (PELLET, et al., 2003, p. 631, tradução própria).

Outra parte da doutrina percebe que o direito internacional clássico não é capaz de explicar adequadamente a nova e complexa teia de interações e fluxos transnacionais, ou mesmo que o modelo estatal e a dicotomia interno/externo não teriam se esgotado. Assim, o direito internacional deveria se posicionar como o quadro normativo que regula as interações

\footnotetext{
${ }^{20}$ Com capacidade limitada, mas tanto em sua forma ativa quanto passiva para a sua efetiva atuação ou responsabilização.

${ }^{21}$ Segundo Alain Pellet, a tese do contrat sans loi "criou uma ordem jurídica independente e constituí a única lei das partes." (PELLET, et al., 2003, p. 631, tradução própria).

${ }^{22}$ Se entendermos contrato como sendo um acordo de vontades (que não segue necessariamente nenhum aspecto formal, e cujo acordo se manifesta na convergência de interesses) que pode se manifestar tácita ou expressamente, e considerarmos estes regimes como sendo convergências de expectativas dos atores em uma determinada área visando a cooperação, em última instância, poderia-se equiparar estes regimes a uma forma sui generis de consagração contratual, apesar de estarmos, neste ponto, nos referindo ao contrat sans loi.
} 
tão somente entre os Estados, as Organizações Internacionais e os poucos sujeitos de direitos derivados que ele já reconhece e assume no mesmo sentido em que atualmente a Organização das Nações Unidas reconhece as ONGs e outras articulações da sociedade civil (art. 71 da Carta), mas somente deveria apreciar os conflitos contenciosos dos Estados ou feitos através do instituto da proteção diplomática no modelo da Corte Internacional de Justiça (art. 34 do Estatuto da Corte Internacional de Justiça). Esta concepção clama pela permanência do direito internacional clássico e, em alguns casos, sugere a criação de um novo ramo do direito como, por exemplo, um direito transnacional. Assim, estes autores admitem a existência de profundas mudanças no cenário internacional e o surgimento de novas relações normativas no sistema, sendo deste modo pluralistas, mas são exclusivistas ao excluírem estas relações da esfera do direito internacional. Neste sentido, estes regimes constituiriam ordens jurídicas autônomas, distintas do direito internacional do direito interno. É grande, por exemplo, o número de autores que reivindicam uma ordem normativa própria para a lex mercatoria, a lex sportiva internationalis. O problema desta posição é que, sem a tutela do Estado, abriríamos espaço para quadros normativos criados pela sociedade incivil internacional como, por exemplo, por grupos narcotraficantes e terroristas. Criticando esta postura, Alain Pellet vai afirmar que:

"[...] outros autores preconizaram submeter os contratos transnacionais a uma 'terceira ordem jurídica'. Para uns, esta ordem inédita seria constituída por princípios gerais de direito, para outros, por um conjunto de práticas habitualmente seguidas na matéria (direito 'transnacional' consuetudinário). Na verdade, se nada se opõe à aplicação das normas em questão, podemos seriamente duvidar que elas constituam uma ordem jurídica autônoma." (PELLET, et al., 2003, p. 631, tradução própria).

Independentemente destas diferentes visões acerca de qual deve ser a postura do direito internacional diante das mudanças aqui descritas, não se pode negar que elas estão em curso no sistema internacional e já implicaram em vicissitudes não somente no direito internacional, mas no direito como um todo. Não podemos nos esquecer que o direito está intimamente ligado à realidade social no qual ele é interpretado e aplicado. Inevitavelmente, grandes mudanças na realidade social acabam por impactar o direito. Valores como o jus cogens, por exemplo, surgem como fonte universal do direito internacional desafiando o controle e fronteiras estatais. A produção normativa se torna transnacionalmente ainda mais 
difusa e descentralizada ao mesmo tempo em que a produção normativa no direito internacional clássico se torna mais centralizada. A ordem estatal paradoxalmente é questionada e se afirma, o direito ressurge nas interações como um instrumento que objetiva a conduta e por isto é capaz de fornecer e consolidar garantias para os atores diante deste cenário tão contingente e fugaz. ${ }^{23} \mathrm{O}$ direito deve refletir, ao menos em parte, as expectativas da realidade do sistema internacional, e por isso, o direito internacional tem caminhado lentamente em sua história, mas sempre continuará caminhando de forma que lentamente as mudanças vão sendo incorporadas, sob o risco da sua própria morte.

\section{4) NOVOS ATORES OU SUJEITOS DE DIREITO INTERNACIONAL?}

Por fim, após uma rápida consideração das implicações do surgimento de novos atores e regimes meta-jurídicos para o direito internacional, deve-se ter em conta que os atores transnacionais (isto é, a sociedade civil, as ONGs, as empresas multinacionais, os especuladores, etc.) interagem no sistema internacional produzindo importantes efeitos normativos. Portanto, se retornarmos para a ideia romana de personalidade 'soar através do cenário do direito', não nos resta dúvida alguma de que os atores transnacionais são atores do sistema internacional e deveriam receber a devida atenção do direito internacional e mesmo a consideração de sua dotação de personalidade jurídica, embora seja razoável que esta seja derivada e em diferente grau do que a personalidade estatal e mesmo das organizações internacionais. ${ }^{24} \mathrm{~A}$ doutrina parece acompanhar este entendimento, uma vez que Pellet nos ensina:

"A descrição do seu regime jurídico [das organizações não governamentais e outras associações civis sem fins lucrativos] nas suas relações com os sujeitos principais de direito internacional mostra com evidência que esta personalidade é 'derivada, funcional e relativa'.Por via de consequência, as capacidades jurídicas que nós podemos deduzir, a gama de direitos e obrigações implicados são bastantes mais variáveis que para as companhias multinacionais: não existe aqui a relativa uniformidade de objetivos deduzidos da finalidade lucrativa das empresas multinacionais." (PELLET, et al., 2003, p. 639, tradução própria).

\footnotetext{
${ }^{23}$ Deve-se ressaltar, contudo, que os valores e práticas objetivantes do direito internacional têm um discurso universalista e, desta forma, deve haver o cuidado para que ele não se transforme em um instrumento de dominação ou imposição de valores que escondem em sua dita "universalidade" interesses egocêntricos.

${ }^{24}$ Um exemplo desta diferença de grau é o caráter excepcional do recurso dos atores transnacionais aos processos internacionais.
} 
Percebe-se nestes dois parágrafos que Alain Pellet reconhece que as ONGs e as multinacionais deveriam ser dotadas de personalidade ${ }^{25}$ jurídica internacional. Note-se que a definição de ONG que o autor adota é bastante ampla (a do art. $1^{\circ}$ da Convenção de Estrasburgo, em que o próprio autor afirma que "a diversidade dos objetivos perseguidos é quase infinita") (PELLET, et al., 2003, p. 636, tradução própria). Isto nos autoriza a concluir que os atores transnacionais deveriam ser dotados de personalidade jurídica de direito internacional $^{26}$ e seus regimes meta-jurídicos virem a ser regulamentados por este.

A consideração acerca dos atores transnacionais como sujeitos de direito internacional é de extrema importância na medida em que permite que o sistema do direito internacional crie mecanismos e instrumentos capazes de regulamentar os fluxos e atuação destes atores no sistema internacional. Se for verdade que a sociedade civil e as ONGs têm se revelado como um forte instrumento de controle e reivindicação democrática, uma vez que operam com uma racionalidade substantiva que se opõe à racionalidade instrumental, o oposto também é verdadeiro. Os atores, ao reclamarem por validade de seu regime ou a autonomia de ação, desvinculam-se de suas lealdades nacionais ou de qualquer ordem legal. Ainda, como os próprios atores negociam as regras dentro do regime, abre-se espaço para que estes o façam baseados em relações de força e poder, orientados teleologicamente pela razão instrumental ou por interesses egoísticos como, por exemplo, quando as grandes empresas ou os grandes investidores determinam as regras com as quais os demais atores, inclusive os Estados, devem se conformar se quiserem ser alvos do investimento. Outro exemplo de problemas que podem acontecer ocorre quando uma ONG transnacional promete uma determinada ajuda a um Estado que deixa de alocar recursos para a área em questão, uma vez que espera a atuação da Organização, e esta simplesmente resolve atuar em outra área ou desiste da ajuda deixando o governo em situação difícil. Outra questão que se levanta é a da

\footnotetext{
${ }^{25}$ Para Caio Mário a capacidade é "uma consequência natural e lógica da personalidade que lhes reconhece o ordenamento legal." (PEREIRA, 1997, p.195).

${ }^{26}$ Neste trabalho não desenvolvemos completamente o tema do indivíduo, apesar de a questão ser objeto de acirrados debates uma vez que autores como Georges Scelle argumentam que a sociedade internacional é uma sociedade de indivíduos no qual o direito das gentes se aplica diretamente, e outros negam completamente o indivíduo como sujeito de direito internacional. Todavia há que se ressaltar a crescente importância do indivíduo para o direito internacional demonstrado pelas regras e valores dos direitos humanos, direito humanitário, e o fortalecimento do direito internacional penal. Por fim, é importante mencionar o parecer consultivo da CPJI de 3 de Maio de 1928, relativo ao caso da Competência dos Tribuanis de Dantzig, no qual a Corte afirmou que "é incontestável que o objeto próprio de um acordo internacional na intenção das partes contratantes possa ser a adoção pelas partes de regras detrminadas que criem direitos e obrigações para os indivíduos e sucetíveis de serem aplicadas pelos tribunais nacionais [...] mas segundo um princípio de direito internacional bem estabelecido, um acordo internacional não pode, como tal, criar diretamente direitos e obrigações para os particulares." Ver CPJI Série B, no. 11, pp.1 à 45.
} 
representação e da responsabilidade diante da ideia de cidadania global acompanhada por uma accountability. Como o indivíduo será representado? Quais as formas de controle representante-representado? A quem um ator transnacional realmente representa? Quais os limites de sua responsabilidade e como responsabilizá-lo?

É importante estar atento a estas e outras perguntas, uma vez que as articulações transnacionais na forma de regimes meta-jurídicos constituem verdadeiras ordens jurídicas paralelas que podem demandar uma validade global e podem se constituir em uma estrutura normativa mutável conforme a conjuntura. Isto pode ocorrer quando estes ordenamentos mantêm seus princípios estruturantes mas reformulam suas regras. Este fenômeno pode levar a criação de uma ordem normativa transnacional extremamente contingente e conferir uma nova importância ao costume enquanto fonte do direito internacional. É bastante exemplificativo a maneira como Teubner discorre sobre o regime da lex mercatoria e das grandes multinacionais:

\begin{abstract}
"É um direito que cresce e muda conforme as exigências das transações e organizações econômicas globais. [...] Isto o torna [o regime da lex mercatoria] extremamente vulnerável a interesses e poder de pressão dos processos econômicos. Uma vez que não existe nenhuma barreira institucional da sua quasi-legislação e quasi-jurisdição, a autonomia e independência relativas a que os ordenamentos legais foram capazes de chegar, irá provavelmente se tornar algo desconhecido. Em um futuro vislumbrável, a lex mercatoria será um direito corrupto - no sentido técnico do termo latino corrumpere. Ao mesmo tempo, a falta de autonomia institucional torna este direito vulnerável à pressões políticas em sua busca pela legitimação. (TEUBNER, 1997. P. 19, tradução própria).
\end{abstract}

Da mesma forma que esta afirmação é verdadeira para a lex mercatoria, elas também o são para outros regimes meta-jurídicos em que os atores se articulam instrumentalmente em regimes marcado internamente por grandes assimetrias de poder entre os atores. É neste aspecto que os novos atores transnacionais e suas interações no sistema se lançam como um grande desafio para o direito internacional, principalmente quanto às responsabilidades dos atores. O desafio se torna ainda maior, por fim, uma vez que estes regimes "corruptos" se fundamentam mais em princípios e valores do que em um ordenamento de estruturas e regras. Desta forma, a sua estabilidade surge exatamente da dificuldade do direito internacional em normatizar estes atores: a estabilidade surge de sua 
maleabilidade diante do contexto do sistema. Estes regimes são contingentes e maleáveis, mas não fracos.

\section{5) CONCLUSÃO}

As recentes transformações do sistema internacional em muito têm impactado os sistemas jurídicos. A distinção entre o direito internacional e o direito interno está cada vez menos clara. ${ }^{27}$ Setores tanto da sociedade civil quanto incivil que antes não possuíam autonomia de ação no sistema internacional adquirem a capacidade de construirem quadros meta-jurídicos de regulamentações de suas condutas. ${ }^{28}$ Estes processos transnacionais colocam a eficácia do direito internacional em regular a vida internacional sob intensa pressão.

Este problema se magnifica quando tratamos de atores transnacionais que se utilizam da força para coagir os Estados. As recentes transformações estruturais do sistema internacional trouxeram à tona uma série de insuficiências no processo de segurança coletiva, ao mesmo tempo em que os atentados terroristas de 11 de setembro de 2001 deixaram uma marca indelével de medo, insegurança, perplexidade e impotência na comunidade internacional, pressionando pela sua permanência. Eventos como este tornaram patente a incompatibilidade da estrutura tradicional do direito internacional para a manutenção da paz internacional frente às ações transnacionais e não estatais. O problema é que, mesmo ao reconhecer a possibilidade de que atores transnacionais se constituam como uma ameaça à paz e segurança internacionais, a estrutura da Carta das Nações Unidas e seus processos foram formulados de uma maneira estatocêntrica que se mostra incapaz de evitar o surgimento de uma nova sombria realidade, na qual a violência passou a ter autor desconhecido e seus alvos tornaram-se difusos. O vínculo multidimensional direto entre as novas esferas da atividade criminosas transnacionais e a comunidade internacional clamam pela criação de mecanismos eficazes de controle e repressão, nesta temática que se mostra extremamente complexa e difusa. Assim, levanta-se inicialmente a questão de saber qual é o papel do direito internacional frente a esta nova realidade?

Certamente, a busca por estas respostas evidencia a necessidade do direito internacional também se adaptar aos novos desafios gerados a partir do incremento de ações transnacionais tanto civis quanto incivis. Todavia, esta exigência vai se deparar, em um primeiro momento, com a dificuldade, reflexo das próprias contradições da comunidade

\footnotetext{
${ }^{27}$ Veja-se, por exemplo, a primazia das correntes monistas.

${ }^{28}$ Veja-se, por exemplo, a lex mercatoriae.
} 
internacional, em se criar mecanismos efetivos de controle desta ordem transnacional. A importância primeira da jurisdicionalização internacionalmente aceita dos fluxos transnacionais reside na necessidade de se distinguir os eventos normatizados pelo direito das áreas em que há apenas um julgamento de valor. A atual lacuna existente abre uma margem perigosa para que o alcance das respostas estatais aos fluxos transnacionais seja variável e aberta ao jogo da política internacional sem fundamento no direito ou em uma busca pela justiça. Como disse Lacordaire "entre fortes e fracos a liberdade oprime e o direito liberta".

\section{BIBLIOGRAFIA}

ARENAL, Celestino del. Introduccion a las Relaciones internacionales. Madri: Tecnos, 1994.

BRANT, Leonardo N. C. (org.) Terrorismo e Direito: Os Impactos do Terrorismo na Comunidade Internacional e no Brasil - Perspectivas Político-Jurídicas. Rio de Janeiro, Forense, 2003.

BULL, Hedley. A Sociedade Anárquica. Brasília: EdUnB, 2002.

BURTON, John W. "World Society" in KAUPPI, Mark V.; VIOTTI, Paul R. International Relations Theory: Realism, pluralism, globalism. Nova York: $2^{\text {nd }}$ edition, ed. MacMillan Publishing Company, 1993.

KEOHANE, Robert O; NYE JR., Joseph (orgs.) Transnational Relations and World Politics. Harvard: Harvard University Press, 1971.

LAKATOS, Imre. The Methodology of Scientific Research Programmes. Cambridge: Cambridge University Press, 1978.

LUHMANN, Niklas. Social Systems. Stanford: Stanford University Press, 1995.

MELlO, Celso D. de A. O Direito Internacional Público em Transformação. São Paulo: PUC/RJ; Resenha, 1976

MORGEnTHAU, Hans J. A Política Entre as Nações: A Luta pelo Poder e pela Paz. Brasília: EdUnB, 2003. 
PELLET, Alain. "As Novas Tendências do Direito Internacional: Aspectos Macrojurídicos" in BRANT, Leonardo N. C. (org.) O Brasil e os Novos Desafios do Direito Internacional. Rio de Janeiro, Forense, 2004.

PELLET, Alain et al. Droit International Public. Paris: LGDJ, 2003.

PEREIRA, Caio M. da S. Instituições de Direito Civil: vol.I. Rio de Janeiro, 1997

ROSENAU, James. Turbulence in World Order. Princenton: Princenton University Press, 1990.

TEUBNER, Gunther (org.). Global Law Without a State. Vermont: Athenaeum Press, 1997. 